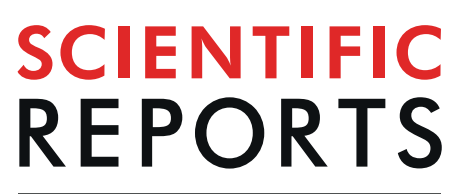

natureresearch

Received: 4 June 2019

Accepted: 9 August 2019

Published online: 22 August 2019

\section{Insoluble solids at high concentrations repress yeast's response against stress and increase intracellular ROS levels}

\author{
Antonio D. Moreno $\mathbb{1}^{1}{ }^{1}$, Cristina González-Fernández $(\mathbb{1})^{2}$, Mercedes Ballesteros $\mathbb{D}^{1,2}$ \& \\ Elia Tomás-Pejóo $\mathbb{1}^{2}$
}

Lignocellulosic ethanol production requires high substrate concentrations for its cost-competitiveness. This implies the presence of high concentrations of insoluble solids (IS) at the initial stages of the process, which may limit the fermentation performance of the corresponding microorganism. The presence of 40-60\% IS (w/w) resulted in lower glucose consumption rates and reduced ethanol volumetric productivities of Saccharomyces cerevisiae F12. Yeast cells exposed to IS exhibited a wrinkled cell surface and a reduced mean cell size due to cavity formation. In addition, the intracellular levels of reactive oxygen species (ROS) increased up to $40 \%$. These ROS levels increased up to $70 \%$ when both lignocellulose-derived inhibitors and IS were simultaneously present. The general stress response mechanisms (e.g. DDR2, TPS1 or ZWF1 genes, trehalose and glycogen biosynthesis, and DNA repair mechanisms) were found repressed, and ROS formation could not be counteracted by the induction of the genes involved in repairing the oxidative damage such as glutathione, thioredoxin and methionine scavenging systems (e.g. CTA1, GRX4, MXR1, and TSA1; and the repression of cell cycle progression, CLN3). Overall, these results clearly show the role of IS as an important microbial stress factor that affect yeast cells at physical, physiological, and molecular levels.

Bioethanol fuel has increased in many countries as an effective alternative to reduce $\mathrm{CO}_{2}$ emissions in the transport sector. The traditional technology for converting sugar- and starch-based feedstocks into ethanol is relatively simple. However, advanced biofuels, such as lignocellulosic bioethanol, hold more opportunities for unlocking the potential of biofuels in order to achieve climate mitigation targets. Although lignocellulosic ethanol started to be commercialized by Beta Renewables back in $2013^{1}$ and several companies have built different industrial-scale plants since then (mainly in the US) ${ }^{2}$, the technology is still being developed due to the high recalcitrant structure of lignocellulose. Such limitation hinders the cost-competitiveness of lignocellulosic ethanol, making necessary further optimization of the biomass processing and microbial conversion steps to implement a fully effective technology.

Simultaneous saccharification and fermentation (SSF) and consolidated bioprocessing (CBP) have appeared as very attractive options for a cost-effective lignocellulosic ethanol production ${ }^{3,4}$. These strategies benefit from the integration of saccharification and fermentation in a single stage, and the tremendous overall cost savings due to the on-site enzyme production ${ }^{5}$. Working at high substrate loadings is also crucial for a cost-effective ethanol production, since this strategy minimizes distillation costs and reduces freshwater requirements. However, the complexity of the lignocellulosic fermentative medium in the form of solid materials and inhibitory biomass-derived compounds (phenolic compounds, furan derivatives and low molecular weight aliphatic acids) increases at high substrate concentrations, making microbial robustness of utmost importance ${ }^{6}$. The effects of biomass degradation compounds on microbial fermentation performance have been widely studied to understand their inhibitory mechanisms and overcome them ${ }^{7-9}$. However, the potential effects of insoluble solids (IS) (i.e., the water insoluble solids (WIS) fraction from pretreated lignocellulosic biomass) on fermentative microorganisms have been constantly undervalued.

${ }^{1}$ CIEMAT, Department of Energy, Biofuels Unit, 28040, Madrid, Spain. ${ }^{2}$ IMDEA Energy Institute, Biotechnological Processes Unit, 28935, Móstoles, Spain. Correspondence and requests for materials should be addressed to A.D.M. (email: david.moreno@ciemat.es) orE.T.-P. (email: elia.tomas@imdea.org) 
The presence of high concentrations of IS at early stages of SSF and CBP processes may represent an important stress factor for fermentative microorganisms, affecting the fermentation performance and/or the tolerance to biomass-derived inhibitors ${ }^{10,11}$. Friction and/or collision mechanisms between IS and cells occur during mixing and, in consequence, cell morphology may be deformed, even causing the disruption of cell membranes and/or cell death. On the other hand, the effect exerted by the IS might indirectly modulate the gene expression pattern, inducing metabolic changes and altering microbial performance in terms of sugar conversion and/or inhibitory tolerance. Elucidating the variations in gene expression and determining the physiological consequences of IS on fermentative microorganisms are therefore necessary to direct future research actions for the development of more robust strains for the ethanol industry.

The present work evaluates the effects exerted by IS on Saccharomyces cerevisiae F12, focusing in aspects such as fermentation performance, cell viability, cell morphology, accumulation of reactive oxygen species (ROS), and the differences on the gene expression pattern. These results will boost the setting of the physiological and molecular basis towards a comprehensive understanding of the mechanisms beyond the effects exerted by IS on yeast cells, which has been often underestimated.

\section{Materials and Methods}

Microorganism and preinoculum growth. S. cerevisiae F12 was used as fermentative microorganism ${ }^{12}$. This strain presents an industrial background and it was genetically modified for lignocellulosic bioethanol production. Besides, it has been successfully used in bioethanol production processes from lignocellulose ${ }^{13}$. Active cell cultures were obtained by growing one single colony in $100-\mathrm{mL}$ shake flasks with $20 \mathrm{~mL}$ YPD medium $(10 \mathrm{~g} / \mathrm{L}$ yeast extract, $20 \mathrm{~g} / \mathrm{L}$ peptone, $20 \mathrm{~g} / \mathrm{L}$ glucose). Cells were incubated in an orbital shaker at $32^{\circ} \mathrm{C}$ and $150 \mathrm{rpm}$ for $18 \mathrm{~h}$. Then, cells were harvested by centrifugation $\left(3000 \mathrm{~g}, 8 \mathrm{~min}, 25^{\circ} \mathrm{C}\right)$ and diluted with the corresponding medium to get the appropriate inoculum size.

Fermentation tests. The influence of IS on the yeast fermentation capacity was evaluated by subjecting $S$. cerevisiae F12 to fermentation in the presence of increased concentrations of solids. Fermentation assays with $0 \%$, $40 \%$ and $60 \%$ IS $(\mathrm{w} / \mathrm{w})$ were performed in $250-\mathrm{mL}$ shake flasks with $100 \mathrm{~mL}$ YNB media (Conda, Cat.1553.00) supplemented with $20 \mathrm{~g} / \mathrm{L}$ glucose and $7.5 \mathrm{~g} / \mathrm{L}\left(\mathrm{NH}_{4}\right)_{2} \mathrm{SO}_{4}$. After inoculation $(0.5 \mathrm{~g} / \mathrm{L}$ dry weight (DW)), cells were incubated in an orbital shaker at $32^{\circ} \mathrm{C}$ and $150 \mathrm{rpm}$ for $48 \mathrm{~h}$. Samples were periodically withdrawn for determination of extracellular metabolites and cell viability.

Degradation compounds embedded in lignocellulosic WIS fractions may interfere with the RNA extraction procedure $^{14}$, which might lead to misleading conclusions. To ease yeast separation and avoid interferences with analytical methods, 4-mm diameter glass beads (Hecht $\mathrm{Karl}^{\mathrm{TM}}$ 1401/4) were used as IS source instead of pretreated lignocellulosic fibers. The particle size of glass beads was within the common range of pretreated lignocellulosic biomass ${ }^{15}$.

Glucose and ethanol were analyzed by high performance liquid chromatography (HPLC) (Agilent infinity 1260, equipped with a refractive index detector), using an Aminex HPX-87H Ion Exclusion column $\left(50^{\circ} \mathrm{C}\right)$ with $5 \mathrm{mM} \mathrm{H}_{2} \mathrm{SO}_{4}(0.6 \mathrm{~mL} / \mathrm{min})$ as mobile phase.

Cell viability was measured with the Vi-Cell ${ }^{\mathrm{TM}} \mathrm{XR}$ analyzer (Beckmann Coulter).

Statistical analyses were performed using IBM SPSS Statistics v22.0 for MacOs X Software (SPSS Inc.). The mean and standard deviation were calculated from triplicates for descriptive statistics. When appropriate, analysis of variance (ANOVA) with or without Bonferroni's post-test was used for comparisons between assays. The level of significance was set at $95 \%, 99 \%$ or $99.9 \%$.

Intracellular glycogen and trehalose were measured on cells collected after $6 \mathrm{~h}$ and $24 \mathrm{~h}$ of fermentation in the presence of $0 \%$ and $40 \%$ IS (w/w), following the protocol described by Nielsen et al. ${ }^{16}$.

Atomic force microscopy. Atomic force microscopy (AFM) was used to visualize the effects promoted from direct cells-solids interaction. Cells collected after $4 \mathrm{~h}$ of fermentation were first immobilized by mechanical trapping into $25-\mathrm{mm}$ porous polycarbonate membranes (Nuclepore $1 \mu \mathrm{m}$, Whatman), and air-dried for $20 \mathrm{~min}$ prior to attaching it in the specific AFM liquid cell. AFM measurements were performed at room temperature in a Park XE-100 AFM (Park Systems), using dynamic contact mode and constant height screening. The maximum range for the XY scanner was $100 \mu \mathrm{m}$ to allow the screening of $90 \times 90 \mu \mathrm{m}^{2}$. The maximum shift of $z$ was $-6 \mu \mathrm{m}$ $+6 \mu \mathrm{m}$. Differences in topography higher than $12 \mu \mathrm{m}$ were not determined. Morphological changes on the yeast cell surface due to the presence of IS were visualized by using non-contact $\mathrm{Si}_{3} \mathrm{~N}_{4}$ cantilevers (NSG30, NT-MDT) with a nominal spring constant of $40 \mathrm{~N} / \mathrm{m}$, high resonance frequency $(320 \mathrm{kHz})$ and curvature radius lower than $10 \mathrm{~nm}$.

ROS measurement. Intracellular ROS concentration was determined in cells collected $(3000 \mathrm{~g}, 8 \mathrm{~min}$, $25^{\circ} \mathrm{C}$ ) after $4 \mathrm{~h}$ of fermentation under the following conditions: (1) absence of IS, (2) presence of $40 \%$ IS (w/w), (3) presence of $12.5 \%(\mathrm{v} / \mathrm{v})$ lignocellulose-derived inhibitors, and (4) presence of $12.5 \%(\mathrm{v} / \mathrm{v})$ lignocellulose-derived inhibitors and $40 \%$ IS (w/w). The inhibitor mixture (1.5 g/L furfural, $0.4 \mathrm{~g} / \mathrm{L} \mathrm{5-HMF,} 6 \mathrm{~g} / \mathrm{L}$ acetic acid, $2.5 \mathrm{~g} / \mathrm{L}$ for$\mathrm{mic}$ acid, $0.06 \mathrm{~g} / \mathrm{L}$ ferulic acid, $0.03 \mathrm{~g} / \mathrm{L}$ syringaldehyde, $0.1 \mathrm{~g} / \mathrm{L}$ vanillin, and $0.05 \mathrm{~g} / \mathrm{L}$ coumaric acid) was prepared according to compounds and concentrations commonly found in steam-exploded lignocellulosic hydrolysates ${ }^{13}$.

ROS accumulation was monitored by flow cytometry using dihydroethydium (DHE) as the ROS indicator. Cell pellets of about $10^{6}$ cells were obtained and diluted with $0.5 \mathrm{~mL}$ PBS buffer. Then, DHE was added to a final concentration of $2 \mu \mathrm{M}$, and the mixture was incubated for $30 \mathrm{~min}$ at $37^{\circ} \mathrm{C}$ in dark conditions. DHE permeated into cells and gets oxidized to ethidium when exposed to superoxide in a dose-dependent manner. Ethidium then intercalates with DNA and emits red fluorescence proportional to intracellular $\operatorname{ROS}^{17,18}$. A blue laser $(488 \mathrm{~nm})$ was used for the excitation, and DHE emission was collected at 585/40 nm. A negative control with non-dyed 
cells was used as process checkup. Analysis was performed with a Cytomics FC 500 cytometer (Beckman Coulter) equipped with an FL3 detector (620 BP). In total, 50,000 cells were collected. The specific intracellular ROS level was obtained by normalizing the intracellular ROS concentrations with a negative control of cells non-treated with DHE.

Microarray analysis of differential gene expression. Total RNA was extracted from cells after $4 \mathrm{~h}$ of fermentation in the presence and absence of $40 \%$ IS (w/w). $5-\mathrm{mL}$ samples were withdrawn, cooled on ice, centrifuged $\left(4000 \mathrm{~g}, 2 \mathrm{~min}, 4^{\circ} \mathrm{C}\right.$ ), and cell pellets were rapidly frozen in liquid nitrogen and stored at $-80^{\circ} \mathrm{C}$ until analysis. Total RNA was isolated using Trizol reagent (Invitrogen) according to the manufacturer's protocol, and treated with RNase-free DNase I (Qiagen) to prevent DNA contamination. The concentration and purity of RNA was measured using Omega spectrophotometer. RNA integrity was determined using Bioanalyzer 2100 (Agilent). Only those samples with $260 / 280>1.8 ; 260 / 230>2.0$; and RNA Integrity Number (RIN) $>8.0$ were further analyzed.

Equal amounts of each RNA sample were retro-transcribed to cDNA using random sequence oligonucleotide hexamers as primers. Template RNAs were then degraded with $\mathrm{NaOH}$ and cDNAs were labeled using TdT DNA polymerase and ddUTP-biotin. Labeled cDNAs were processed with GeneChip ${ }^{\circledR}$ IVT PLUS Reagent Kit (Affymetrix ${ }^{\circledR}$ ), hybridized with GeneChip ${ }^{\mathrm{TM}}$ Yeast Genome 2.0 Array (Affymetrix ${ }^{\circledR}$ ) and scanned with a GeneChip ${ }^{\circledR}$ Scanner $30007 \mathrm{G}$ (Affymetrix ${ }^{\circledR}$ ). Raw data were processed with RMA algorithm included in Affymetrix ${ }^{\circledR}$ Expression Console ${ }^{\mathrm{TM}}$ for normalization and gene level analysis. For each experimental condition, three microarray experiments corresponding to three independent RNA replicates were processed and analyzed. First, fold changes between experimental conditions were calculated as a quotient between the mean of the gene expression signals. Statistical analysis was performed with LIMMA package included in Babelomics software package [http://www.babelomics.org $]^{19}$. Those values with a false discovery rates (FDR) $<0.05$ were considered as significant. Genes with Log2-fold change $>1$ or $<(-1)$ were included for further analysis. Furthermore, microarray experiments were analyzed by Piano software [http://biomet-toolbox.chalmers.se] ${ }^{20}$. In this case, FDR $<0.001$ was used as gene selection cut-off in order to identify those differentially expressed genes with a higher statistical significance. Values corresponding to $\mathrm{FDR}<0.05$ were used for obtaining the corresponding heat map.

Microarray data were submitted to the NCBI GEO with GSE115460 as accession number [https://www.ncbi. nlm.nih.gov/geo/query/acc.cgi?acc=GSE115460].

Differentially expressed genes were classified by YeastMine according to their main known/proposed functions $^{21}$. Thus, downregulated and upregulated genes were used to investigate and categorize the gene ontology (GO)-annotations, including both biological processes and molecular functions. Finally, network analysis of known/predicted protein-protein interactions was evaluated using STRING software v10.5 22 .

\section{Results}

Insoluble solids reduce cell viability affecting the fermentation performance. Fermentation tests with $40 \%$ and $60 \%$ IS (w/w) were performed to envisage any effect exerted by IS on the ethanol production of $S$. cerevisiae F12. When using pretreated lignocellulosic biomass, substrate concentrations up to $40 \%(\mathrm{w} / \mathrm{w}$ ) dry matter (DM) have been previously reported ${ }^{23}$. When compared to glass beads, the water retention capacity of biomass reduces the water available for yeast cells during the initial stages of the fermentation processes. In this context, a higher content of glass beads might simulate such effect and, therefore, a concentration of $60 \%$ IS (w/w) was also investigated. The presence of IS during the fermentation process resulted in lower glucose consumption rates and reduced ethanol volumetric productivities at early times, independently of the IS concentration (Fig. 1A). 5.2 \pm 0.6 and $10.5 \pm 1.2 \mathrm{~g} / \mathrm{L}$ of glucose remained in the media after $6 \mathrm{~h}$ of fermentation in presence of $40 \%$ and $60 \%$ IS $(w / w)$, respectively, while total glucose depletion was observed in absence of IS (w/w) (Fig. 1A, Table 1). The decrease in glucose consumption rates led to lower ethanol concentrations and lower ethanol volumetric productivities. Ethanol volumetric productivities were $1.2 \pm 0.0,0.9 \pm 0.0$ and $0.6 \pm 0.1 \mathrm{~g} / \mathrm{L} \mathrm{h}$ for $0 \%, 40 \%$, and $60 \%$ IS $(\mathrm{w} / \mathrm{w})$ assays, respectively (Fig. $1 \mathrm{~A}$, Table 1$)$. In this context, Fig. $1 \mathrm{~B}$ clearly shows a $20-30 \%$ reduction $(P<0.001)$ in cell viability due to the presence of $40 \%$ or $60 \% \mathrm{IS}(\mathrm{w} / \mathrm{w})$ at $6 \mathrm{~h}$ of process, thus explaining the lower glucose consumption rates and the reduced ethanol volumetric productivities when compared to $0 \%$ IS (w/w). However, the absence of differences in viability when comparing $40 \%$ and $60 \%$ IS (w/w) does not explain the disparity in glucose consumption at $6 \mathrm{~h}$, which may be connected to metabolic and gene expression changes.

The final ethanol concentration was clearly dependent on the IS content (Fig. 1A, Table 1). In presence of $40 \%$ IS $(w / w)$, similar ethanol concentrations $(7.0 \pm 0.1 \mathrm{~g} / \mathrm{L})$ to those observed in the absence of solids $(7.3 \pm 0.0 \mathrm{~g} / \mathrm{L})$ were attained at $24 \mathrm{~h}$. However, due to the lower cell viability and the lower glucose consumption rates, the peak for maximum ethanol concentration was delayed when $40 \%$ IS $(\mathrm{w} / \mathrm{w})$ were present (Fig. 1A). In the presence of $60 \%$ IS, maximum ethanol concentration was $4.3 \pm 0.3 \mathrm{~g} / \mathrm{L}$ (w/w) (Fig. 1A, Table 1), which represents a $42 \%$ reduction $(P<0.001)$ when compared to $0 \%$ and $40 \%$ IS $(w / w)$. In all cases, the ethanol concentration remained constant up to $48 \mathrm{~h}$ of process (Fig. 1A), and there was no glucose consumption after $24 \mathrm{~h}$ in presence of $60 \%$ IS (w/w), even though cell viability was maintained above $60 \%$ (Fig. 1B) with a total cell population of $42.4 \pm 2.6$ Mcells/mL (52.9 \pm 1.4 Mcells/mL were observed at $24 \mathrm{~h})$.

Insoluble solids directly promote changes in cell morphology and increase intracellular ROS. Cells exposed to an external chemical or physical stressor have previously shown important changes on cell surface $e^{24,25}$. To determine any variation on the cell surface and size, cells collected after $6 \mathrm{~h}$ of fermentation in the presence and absence of IS were visualized by AFM, since the yeast performance was severely affected at this time point. As shown in Fig. 2, cells markedly changed their cell surface topography from a round-turgid shape in the absence of IS (Fig. 2A) to a highly wrinkled morphology when solids were present (Fig. 2B). These changes were 
A
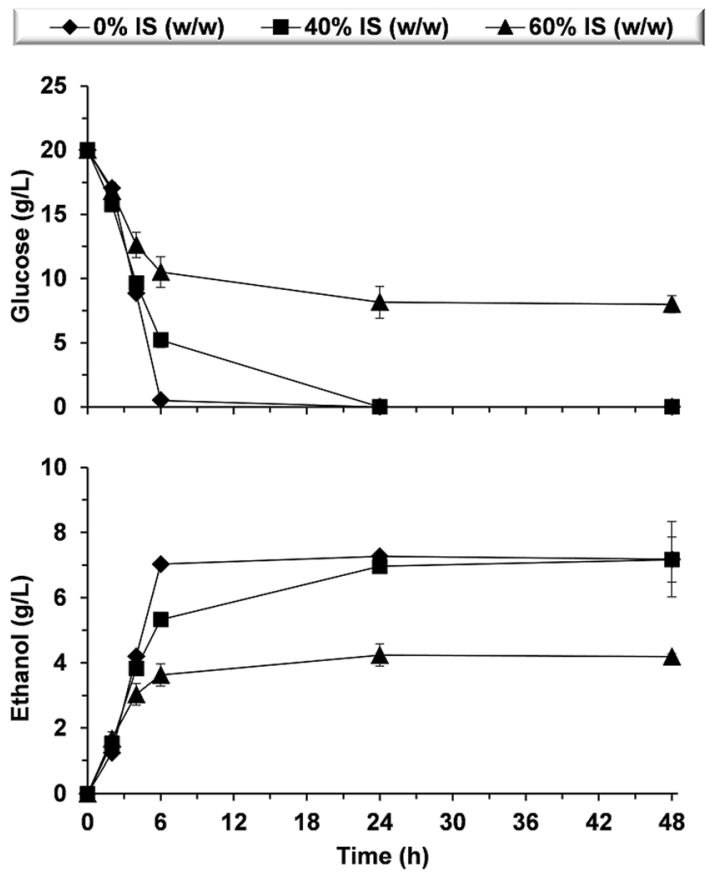

B
$0 \%$ IS $(w / w)$
$\square 40 \%$ IS (w/w)
$\square 60 \%$ IS (w/w)

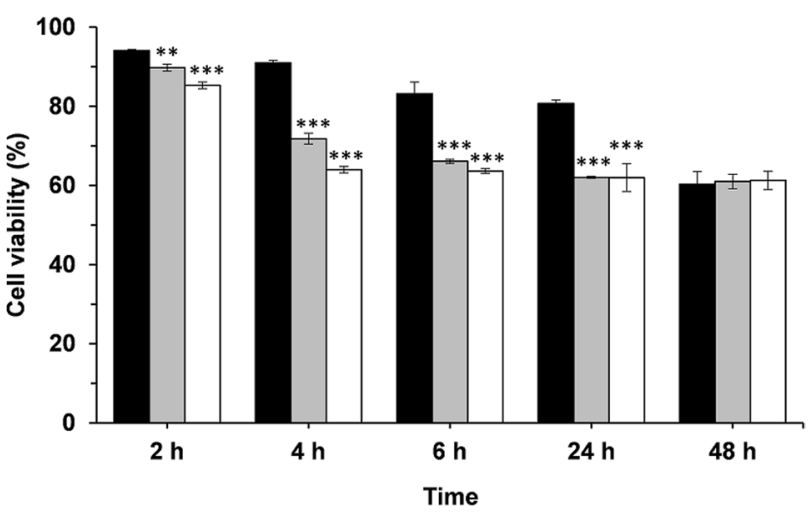

Figure 1. Fermentation performance of S. cerevisiae F12 in the presence and absence of insoluble solids (IS). Time-course for $(\mathbf{A})$ glucose consumption and ethanol production, and (B) cell viability. Significant differences: $* * P<0.01, * * * P<0.001$.

\begin{tabular}{|l|l|l|l|l|}
\hline & Ethanol $_{\max }(\mathbf{g} / \mathbf{L})$ & Yield $_{\mathrm{E}}(\mathbf{g} / \mathbf{g})^{\mathbf{a}}$ & $\mathbf{Q}_{\mathrm{E}}(\mathbf{g} / \mathbf{L} \mathbf{~ h})^{\mathbf{b}}$ & Glucose $_{6 \mathrm{~h}}(\mathbf{g} / \mathbf{L})^{\mathbf{c}}$ \\
\hline $0 \%$ IS (w/w) & $7.3 \pm 0.0$ & $0.37 \pm 0.00$ & $1.2 \pm 0.0$ & $0.0 \pm 0.0(0 \%)$ \\
\hline $40 \%$ IS (w/w) & $7.0 \pm 0.1$ & $0.35 \pm 0.00$ & $0.9 \pm 0.0$ & $5.2 \pm 0.6(26 \%)$ \\
\hline $60 \%$ IS (w/w) & $4.3 \pm 0.3$ & $0.22 \pm 0.01$ & $0.6 \pm 0.1$ & $10.5 \pm 1.2(53 \%)$ \\
\hline
\end{tabular}

Table 1. Fermentation parameters in presence and absence of insoluble solids (IS). ${ }^{a}$ Ethanol yields were determined as follows: [Ethanol $\left.\max _{\max }\right] /\left[\right.$ glucose $\left._{\text {initial }}\right]$. ${ }^{\mathrm{b}}$ Ethanol volumentric productivities were estimated at $6 \mathrm{~h}$

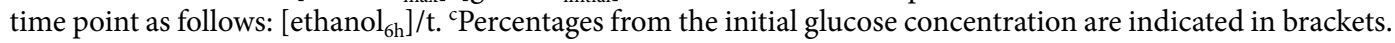

mainly promoted by the formation of cavities, which also caused a reduction in the mean cell size from 6.0 to $5.4 \mu \mathrm{m}(P<0.001)$ (Fig. 2C).

ROS accumulation is another effect typically induced by exogenous stress factors ${ }^{26}$. In this work, ROS accumulation was evaluated in the presence of $40 \%$ IS (w/w) after $4 \mathrm{~h}$ of fermentation. The time point was chosen according to the better viability observed (ROS content is evaluated on viable cells) when compared to the 6-h time point (Fig. 1B). Low ROS levels were measured in the absence of IS. In contrast, above $45 \%(P<0.001)$ of the viable cell population subjected to fermentation in the presence of $40 \%$ IS (w/w) showed high ROS levels, with almost $30 \%$ of them evidencing severe damage $(P<0.001)$ (Fig. 3$)$. With the aim of evaluating any potential 
A

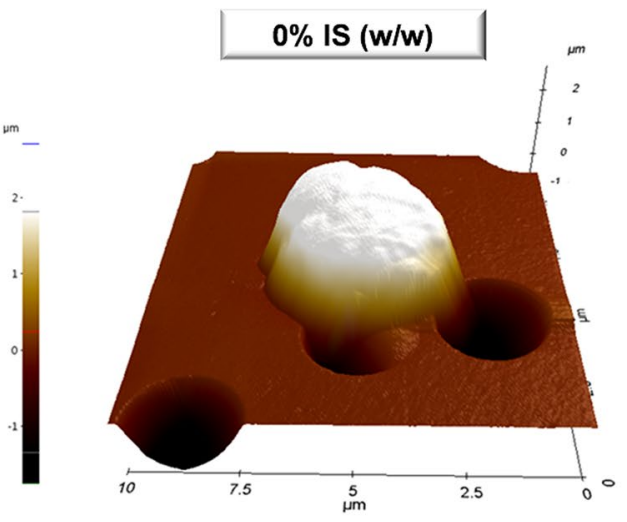

B

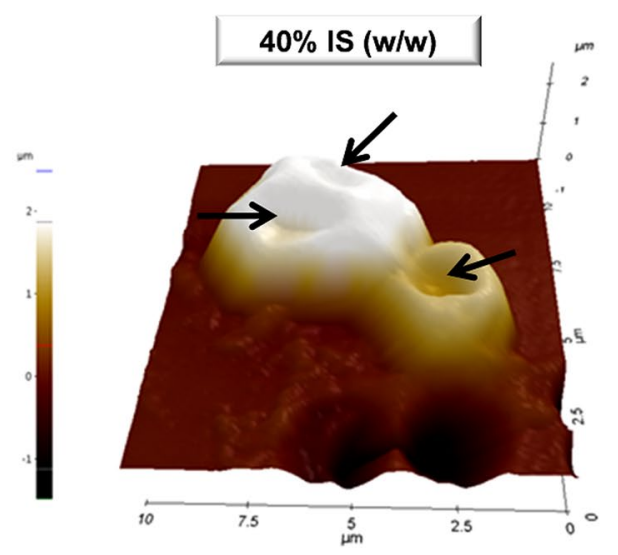

C

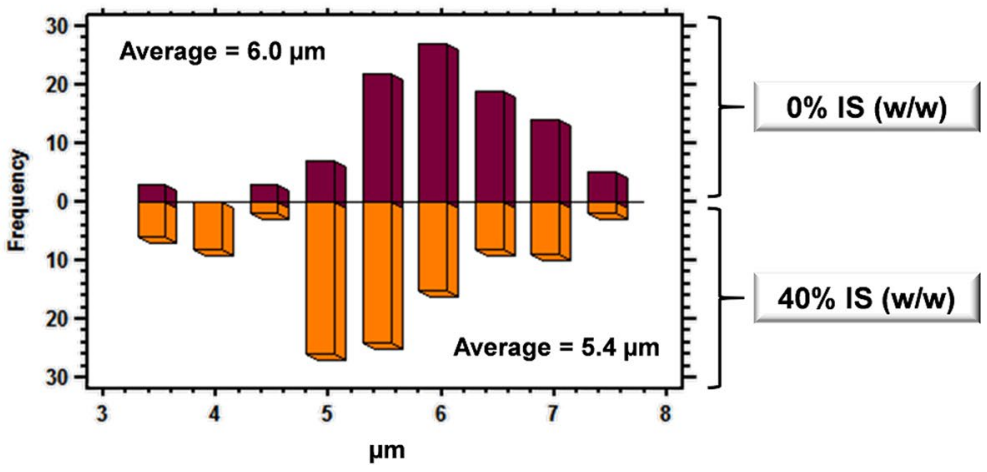

Figure 2. AFM imaging of S. cerevisiae F12 exposed to $0 \%$ and $40 \%(\mathrm{w} / \mathrm{w}$ ) insoluble solids (IS). (A,B) 3D-reconstruction from $10 \mu \mathrm{m} \times 10 \mu \mathrm{m}$ AFM topographic images. (C) Cell size distribution in presence and absence of IS. Arrows are indicative of cavity formation.

synergy with lignocellulosic-derived compounds, ROS levels were also measured in cells growing in the presence of inhibitors with or without IS. The cell population subjected to fermentation in presence of $12.5 \%(\mathrm{v} / \mathrm{v})$ lignocellulose-derived compounds showed, in general, low ROS levels in the absence of IS. Nonetheless, the cell percentage showing high ROS levels increased up to $70 \%(\mathrm{P}<0.001)(35 \%$ of which showed severe damage) when IS and lignocellulose-derived inhibitors were simultaneously present.

Gene expression pattern in the presence of insoluble solids. The presence of IS might also influence yeast cell physiology by modulating the gene expression pattern. Differential expression analysis (FDR $<0.05)$ identified 200 genes overexpressed and 513 genes downregulated after $4 \mathrm{~h}$ of fermentation in the presence of $40 \%$ IS (w/w) (Fig. 4A). These values represent the $11 \%$ equivalent of the total gene number in S. cerevisiae (6433 genes) [https://www.yeastgenome.org]. Differences in gene expression were identified by using the Log2-fold change $\operatorname{method~}^{27}$ and Piano software ${ }^{20}(\mathrm{FDR}<0.001)$, showing above $40 \%$ matches $(292$ genes) between them. In addition, a heatmap using hierarchical clustering was built based on differentially expressed genes (FDR $<0.05$ ) with the aim of grouping samples with similar data. This plot clearly identified two different clusters (Fig. 4B): (i) one corresponding to cells collected during fermentation in presence of $40 \%$ IS (w/w), and (ii) one corresponding to cells collected in absence of solids. These results support the differences on the gene expression pattern between cell populations.

The main biological processes influenced by the presence of IS were determined by gene ontology analysis. Table 2 shows the enriched upregulated and downregulated biological processes, respectively (FDR $<0.05$ ). Small molecule and sulfur metabolic processes, including amino acids biosynthesis, carboxylic acid metabolic processes, glutathione biosynthesis, etc., and processes involved in transportation and respiration were identified as major overexpressed biological processes in the presence of IS. In contrast, carbohydrate metabolic processes (trehalose and glycogen biosynthesis), cell response to stimulus (DNA repair, response to heat, desiccation or drugs) and certain general biological regulation mechanisms (regulation of gene expression, RNA biosynthesis, signal transduction, etc.) were, on the other hand, repressed by the presence of IS. Enrichment analysis of differentially expressed genes could also identify specific repressed and overexpressed $(P<0.01)$ metabolic pathways (Table 3). Thus, glycogen and trehalose biosynthetic pathways, and the oxidative branch of the pentose phosphate pathway were found to be downregulated, while sulfate assimilation pathway and superpathway of sulfur amino acid biosynthesis were upregulated in the presence of $40 \%$ IS (w/w). Downregulation of glycogen and trehalose biosynthetic pathways was also supported by actual metabolite concentrations (Supplementary Fig. S1). After $6 \mathrm{~h}$ of fermentation, trehalose content was below the detection limits, while glycogen content was $260 \pm 18$ and $147 \pm 25 \mathrm{mg} / \mathrm{g}$ DM $(P<0.01)$ for $0 \%$ and $40 \%$ IS $(\mathrm{w} / \mathrm{w})$, respectively. After $24 \mathrm{~h}$, trehalose content was $4.7 \pm 1.3$ 


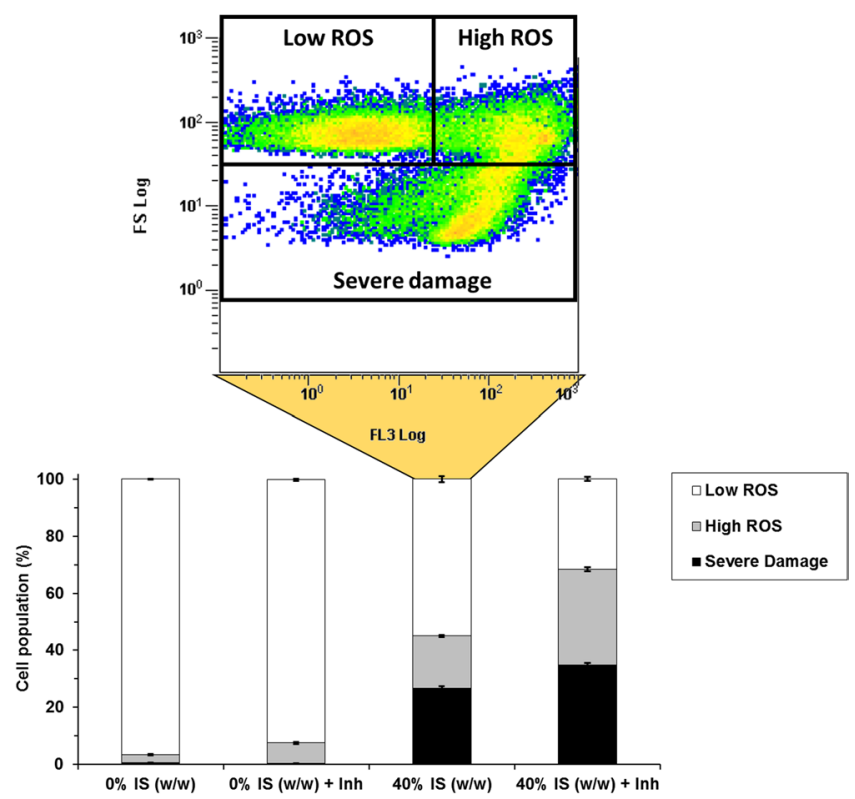

Figure 3. Accumulation of reactive oxygen species (ROS) in S. cerevisiae F12 in presence and absence of $40 \%$ (w/w) insoluble solids (IS), lignocellulosic-derived inhibitors (Inh), and both IS and Inh. Raw data from sample $40 \%$ IS (w/w) are visualized as an example for populations grouping. Low ROS cells were defined as cells adjusted to the negative control. High ROS cells were assigned to those reaching the highest levels of fluorescence. High levels of ROS together with low cell sizes were assigned to cells presenting severe damage.

and $0.5 \pm 0.2(P<0.01)$ for $0 \%$ and $40 \%$ IS $(w / w)$, respectively, while no differences on glycogen content were found $(130-140 \mathrm{mg} / \mathrm{g} \mathrm{DM})$.

It is important to highlight that most of the differentially expressed genes (194 out of 513 downregulated genes, and 53 out of 200 upregulated genes) had, however, an unknown molecular function, and 30-40\% of them encoded a putative protein with unknown function (Supplementary Table S1). Above $80 \%$ and $60 \%$ of these repressed and overexpressed genes had a Log2-fold change above one order, respectively, which may indicate a potential role in the cell response to IS. Indeed, although having an unknown molecular function, the upregulated genes CIR2, KNH1, MIX17, YDL012C, and YGR266W and the downregulated genes BIR1, DDR2, EIS1, FUN19, IZH4, MTL1, RGI1, SPI1, STF2, TMC1, YBL111C, YDR391C, YIL108W, YJL144W, YKR011C, YLR149C, and YRO2 have been previously identified with a key role in the cell response to stress (Supplementary Table S1).

To bring more light in the differences found, differentially expressed genes were also analyzed by STRING software [http://string.embl.de/], which establishes the interaction between proteins that contribute together to the same function. Figure 5 illustrates the most significant protein-protein interactions (highest confidence score), grouped according to biological processes. Also, Table 4 shows the complete gene list resulted from STRING analysis. Overall, STRING and ontology analyses led to similar results, emphasizing the importance of protein metabolic processes, stress-response mechanisms, cell cycle regulation, and carbohydrate and lipid metabolic processes as the main biological processes influenced by the presence of IS.

Protein metabolic processes modulated by the presence of IS included genes related to autophagy, protein degradation, and amino acid and protein metabolic processes. In this sense, differentially expressed genes related to autophagy (ATG genes) and protein modification/degradation mechanisms (including proteinases $\mathrm{A}$ and $\mathrm{B}$ ) were both repressed by IS. Meanwhile, genes associated to amino acid biosynthesis (especially those encoding the synthesis of methionine and cysteine) and other protein metabolic processes, such as translation and ribosome biogenesis, were induced (Fig. 5, Table 4). It should be noted that S. cerevisiae F12 simultaneously repressed some of the genes needed for ribosome biogenesis. Besides, certain specific genes related to RNA processing, such as those encoding for the spliceosome, were also repressed, pointing out the high complexity of the cell response to the presence of IS.

Regulation of the cell cycle and the overall yeast stress response were also influenced by the presence IS. Thus, cells subjected to $40 \%$ IS (w/w) downregulated the expression of genes involved in cell division, cell cycle phase transition (including CLN3), chromatin organization, and different DNA recombination and repair mechanisms (Fig. 5, Table 4). Finally, about 30 genes involved in the yeast's general response to stress were differentially expressed, including DDR2, GPX2, GRX1, GRX4, HSP104, HSP30, HSP31, MTL1, TPS1, TSA1, TSA2, and ZWF1, which are recognized as crucial genes to face heat, oxidative and/or osmotic stresses ${ }^{28-31}$. These genes were downregulated in most cases, including the specific genes related to trehalose and glycogen biosynthesis, two important carbohydrates involved in the cell response to stress ${ }^{32,33}$. In contrast, genes involved in the glutathione system, the assembly of Fe-S clusters, or the degradation of allantoin were induced. 
A

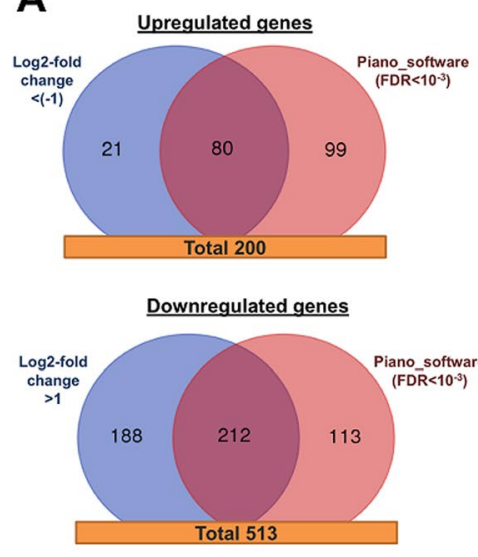

\section{B}

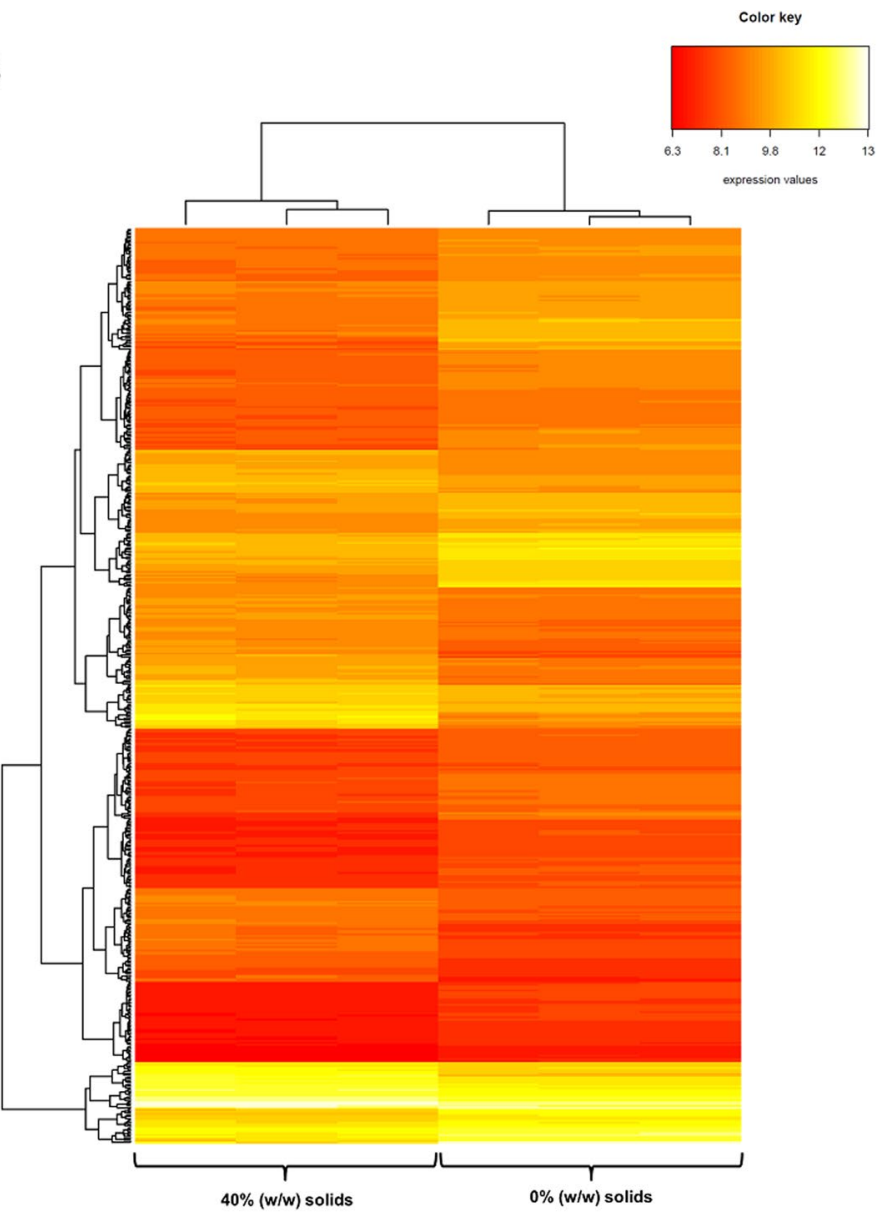

Figure 4. Differentially expressed genes in presence of $40 \%(\mathrm{w} / \mathrm{w})$ insoluble solids (IS). (A) Venn diagrams of upregulated and downregulated gene numbers identified by the Log2-fold change and Piano software. (B) Heatmap and hierarchical clustering of the differentially expressed genes.

\section{Discussion}

The experience gained from brewing and starch-based fermentations under high gravity conditions have paved the way for the application of similar strategies during lignocellulose conversion processes. High gravity technologies are necessary to achieve high substrate concentrations, thus allowing high ethanol titers and reducing distillation $\operatorname{costs}^{34}$. At high substrate loading yeast cells have to deal with a high IS content during SSF/CBP processes, especially at early stages. Notwithstanding, when SSF/CBP proceeds liquefaction effect (due to enzymatic activity) that convert biomass particles into an aqueous paste takes part ${ }^{23}$. IS may produce stress and induce cell damage on fermentative yeasts ${ }^{35}$, although their potential consequences at early stages of SSF/CBP processes have been generally disregarded, and only the effects caused by biomass-derived inhibitors have been usually considered. In this work, S. cerevisiae F12 cells shrank and increased their surface roughness when exposed to IS, highlighting the role of IS as an important stressor during the fermentation processes. Differences in cell morphology have

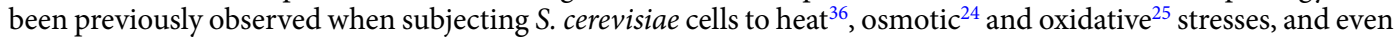
during the stress caused by the presence of high ethanol concentrations ${ }^{37,38}$. However, this is the first time that the changes in cell morphology are evidenced in the presence of IS. Osmostress, thermostress or oxidative stress have also shown to decrease mean cell volumes ${ }^{24,25}$. Similar observations were found in this work, where the mean cell size of cells exposed to IS was reduced by $10 \%$. These results highlight the similarities between the effects promoted by solids and other physical and/or chemical stressors on cell surface.

In addition to induce morphological changes, IS have shown to influence the fermentation performance of yeast cells. The presence of $40 \%$ and $60 \%$ IS (w/w) decreased S. cerevisiae F12 viability by $20-30 \%$, reducing the overall substrate consumption rates and ethanol volumetric productivities. Moreover, although cell population retained about $60 \%$ of cell viability in case of $40 \%$ and $60 \%$ IS (w/w) along the fermentation process, the highest IS content reduced final ethanol titers by 1.7 -fold due to an incomplete glucose utilization. This result might be indicative of metabolic and gene expression changes occurring in cells subjected to $60 \%$ IS (w/w). Indeed, cells might be entering in a resting state when subjected to IS, since quiescence is typically induced to confer increased resistance to a wide range of environmental stress factors ${ }^{39}$. Supporting this hypothesis, 30 genes involved in the regulation of the cell cycle were found to be downregulated in the presence of IS at $4 \mathrm{~h}$ of process, including CLN3, which has been identified to be one of the earliest genes activated to promote the transition between G0 and G1 phases ${ }^{40}$. Quiescent or cell arrest is usually induced by nutrient starvation (e.g. glucose or nitrogen), and 


\begin{tabular}{|c|c|c|c|}
\hline Biological Process & GO Term & Gene $\mathbf{N}^{\circ}$ & $P$-value ${ }^{\text {a }}$ \\
\hline \multicolumn{4}{|l|}{ Upregulated processes: } \\
\hline Small molecule metabolic process $^{1}$ & GO:0044281 & 58 & $6.10 \mathrm{E}-06$ \\
\hline Sulfur compound metabolic process ${ }^{2}$ & GO:0006790 & 21 & $1.53 \mathrm{E}-05$ \\
\hline Oxidation-reduction process ${ }^{3}$ & GO:0055114 & 38 & $1.88 \mathrm{E}-04$ \\
\hline Drug metabolic process ${ }^{4}$ & GO:0017144 & 27 & $3.35 \mathrm{E}-04$ \\
\hline Transmembrane transport ${ }^{5}$ & GO:0055085 & 37 & $6.31 \mathrm{E}-04$ \\
\hline Cellular respiration $^{6}$ & GO:0045333 & 15 & $1.42 \mathrm{E}-02$ \\
\hline \multicolumn{4}{|l|}{ Downregulated processes: } \\
\hline Carbohydrate metabolic process ${ }^{7}$ & GO:0005975 & 53 & $4.91 \mathrm{E}-05$ \\
\hline Response to stimulus $^{8}$ & GO:0050896 & 148 & $6.84 \mathrm{E}-03$ \\
\hline Pyridine-containing compound metabolic process ${ }^{9}$ & GO:0072524 & 23 & 7.23E-03 \\
\hline Biological regulation $^{10}$ & GO:0065007 & 218 & $1.99 \mathrm{E}-02$ \\
\hline
\end{tabular}

Table 2. Upregulated and downregulated biological processes enriched in the presence of insoluble solids (IS) ${ }^{a}$ Multiple testing was analyzed by Holm-Bonferroni test. ${ }^{1}$ Amino acid metabolic process, organic acid metabolic process, sulfur compound metabolic process, TCA metabolic process, respiratory electron transfer chain. ${ }^{2}$ Sulfur compound metabolic process, methionine and cysteine biosynthetic process, drug metabolic process. ${ }^{3}$ Cellular respiration, TCA metabolic process, ATP synthesis coupled electron transport, sulfur metabolic process.

${ }^{4}$ Antibiotic metabolic process, allantoin metabolic process, toxin metabolic process, aerobic respiration, sulfate assimilation. ${ }^{5}$ Transport involving ions, organic acids, amino acids, and sulfate. ${ }^{6}$ Aerobic respiration, TCA metabolic process, electron transport chain. ${ }^{7} \mathrm{Hexose}$ metabolic process, trehalose metabolic process, glycogen metabolic process, gluconeogenesis, pentose-phosphate pathway: oxidative branch. ${ }^{8} \mathrm{Cellular}$ response to stress: chemical, drug, desiccation, temperature, oxidative stress, DNA repair, cell cycle. ${ }^{9}$ Coenzyme metabolic process, phosphorus metabolic process, vitamin metabolic process, ATP generation from ADP. ${ }^{10}$ Cell cycle, regulation of gene expression, ion homeostasis, signal transduction, regulation of primary metabolic process.

\begin{tabular}{|c|c|c|c|}
\hline Metabolic Pathway & Pathway Ref. & Related Genes & P-Value ${ }^{a}$ \\
\hline \multicolumn{4}{|l|}{$\underline{\text { Repressed: }}$} \\
\hline Glycogen biosynthesis & PWY3O-4031 & $\begin{array}{l}\text { GLC3, GLG1, GSY1, } \\
\text { GSY2, PGM2, UGP1 }\end{array}$ & $3.35 \mathrm{E}-03$ \\
\hline Trehalose biosynthesis & TRESYN-PWY & $\begin{array}{l}\text { TPS1, TPS2, TPS3, } \\
\text { TSL1 }\end{array}$ & $8.15 \mathrm{E}-03$ \\
\hline $\begin{array}{l}\text { Oxidative branch of the pentose } \\
\text { phosphate pathway }\end{array}$ & OXIDATIVEPENT-PWY & SOL4, GND2, ZWF1 & $1.33 \mathrm{E}-02$ \\
\hline \multicolumn{4}{|l|}{ Overexpressed: } \\
\hline Sulfate assimilation pathway & PWY-781 & $\begin{array}{l}\text { MET3, MET5, } \\
\text { MET10, MET14, } \\
\text { MET16 }\end{array}$ & $1.08 \mathrm{E}-03$ \\
\hline $\begin{array}{l}\text { Superpathway of sulfur amino } \\
\text { acid biosynthesis }\end{array}$ & PWY-821 & $\begin{array}{l}\text { HOM3, MET2, } \\
\text { MET3, MET5, } \\
\text { MET10, MET14, } \\
\text { MET16, MET17, } \\
\text { STR3 }\end{array}$ & $2.23 \mathrm{E}-03$ \\
\hline
\end{tabular}

Table 3. Gene enrichment analysis of specific metabolic pathways repressed and overexpressed in the presence of insoluble solids ${ }^{a}$ Multiple testing was analyzed by Holm-Bonferroni test.

it is linked to the concomitant repression of ribosomal biogenesis genes and the induction of autophagy- and stress-responsive genes ${ }^{41}$. Ribosome synthesis is one of the major energy consuming processes of the cell, and it must be therefore limited under nutrient-limiting conditions ${ }^{42}$. Autophagy, on the other hand, is required to reallocating limited nitrogen through autophagic degradation of existing proteins and organelles, and/or for vacuolar nutrient sensing in mediating mitotic exit during nutrient starvation ${ }^{43}$. In this work, nutrient-rich conditions were used to evaluate the effects of IS on S. cerevisiae F12 cells, which might explain the induction of ribosome biogenesis and translation genes, and the repression of proteolysis and autophagy-related genes. Notwithstanding, ribosome synthesis is a highly complex process; therefore, certain genes involved in ribosome biogenesis were also found repressed in the presence of IS.

Cell arresting may also be promoted in response to stress-derived DNA damage in order to maintain genomic integrity of proliferating cells ${ }^{44}$. Optimal adaptation to stress involves an extensive reorganization of the gene expression $^{45}$. In addition to repressed cell cycle transition, the presence of IS also influenced the expression of several genes related with the general cell response to stress. The expression of DDR2, TPS1, HSP30, HSP104, MTL1, GRX1, TSA2, and ZWF1 is usually activated by a variety of chemical agents and environmental or physiological stresses $^{28,29,31,46}$. For instance, the multi-stress response gene DDR2 may be activated by more than 13 xenobiotic agents, heat shock, DNA damage and other stresses ${ }^{28}$. TPS1 has been recently identified as a key gene for cell survival during heat stress, oxidative stress or desiccation ${ }^{31}$. The gene encoding for the negative regulator of the 


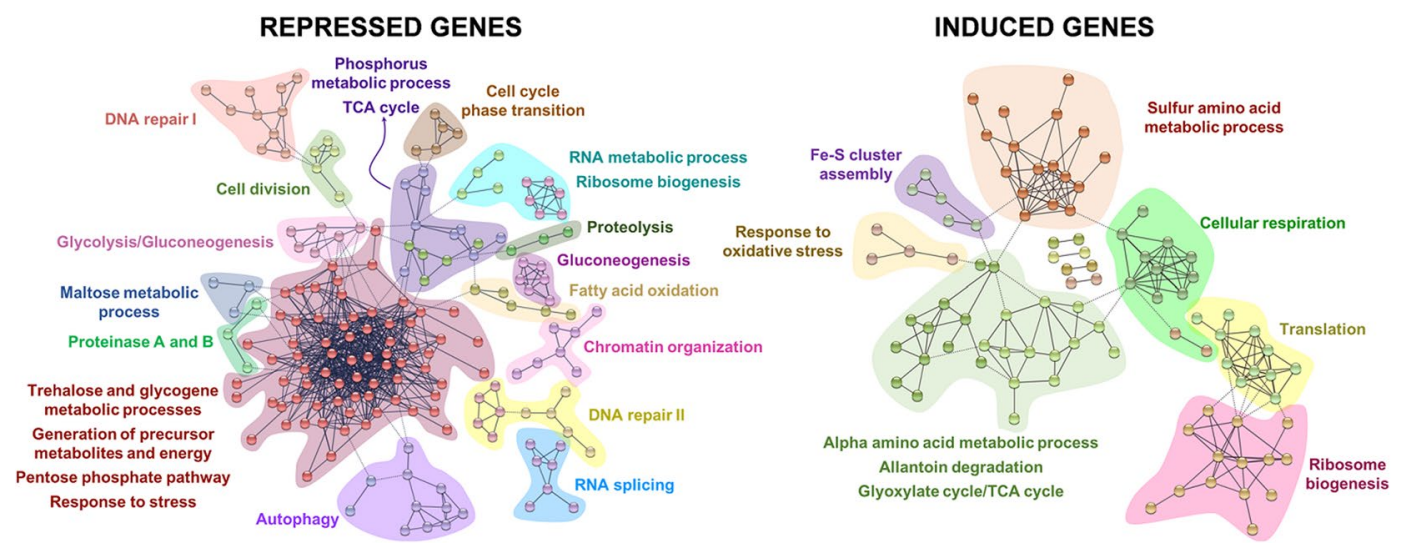

Figure 5. STRING analysis of differentially expressed genes in presence of $40 \%(\mathrm{w} / \mathrm{w})$ insoluble solids (IS). Groups are based on the biological processes in which proteins are involved.

$\mathrm{H}^{+}$)-ATPase (HSP30) and dissagregase protein (HSP104) are also overexpressed upon exposition to ethanol, heat, and osmotic stress ${ }^{46}$. On the other hand, MTL1, GRX1, TSA2, and ZWF1 genes are usually overexpressed in the presence of chemical and oxidative stressors, including the lignocellulose-derived inhibitors furfural and 5 -hydroxymethylfurfural ${ }^{15,29,46,47}$. The absence of proper sensing mechanisms for detecting the external damage promoted by IS might be behind the lack of an effective stress response, thus resulting in a defective activation of the corresponding protective mechanisms and increasing intracellular ROS levels. ROS are an unavoidable by-product of aerobic metabolism commonly accumulated as a consequence of cell exposure to different stressors $^{48}$. In the presence of IS, about $40 \%$ of the cell population evidenced high ROS content. This population percentage was increased by 1.8 -fold when combining IS and lignocellulose-derived inhibitors, even though these compounds caused minor ROS accumulation in the absence of IS. This fact highlights the serious consequences of having such environment during lignocellulose conversion processes at high substrate concentration.

Trehalose and glycogen biosynthetic pathways were also repressed in the presence of IS. These carbohydrates are two glucose storages of yeast cells and they accumulate in response to different environmental changes ${ }^{32}$. Furthermore, trehalose is one of the most effective substances known for preservation of membranous structures and enzyme activities during stress ${ }^{33}$. The lower trehalose levels combined with a high intracellular ROS content may synergistically contribute to increase cell damage, severely affecting DNA (promoting both base damage and strand breaks), proteins and other cellular components, and leading to cell membrane instability as well ${ }^{26}$. Therefore, the overall repression of these stress protective mechanisms besides the increase in ROS levels may negatively contribute to boost morphological changes on cell surface after the direct exposure to IS, also causing a drastic intracellular damage. Surprisingly, direct reversal repair pathway (involving PHR1 gene), base excision repair pathway (involving MAG1 gene), and RAD-related DNA repair pathways (nucleotide excision repair pathway, the homologous recombination pathway, and the postreplication repair pathway ${ }^{49}$ were also downregulated in the presence of IS. Repression of these DNA repair pathways might be responsible for the decrease in cell viability, since all genome mutations caused by the high ROS levels would accumulate, ultimately promoting cell death $^{50}$. This hypothesis is also supported by repression of BIR1 (BIR1 deletion mutants are more sensitive to apoptosis induced by oxidative stress) and STF2 (deletion of STF2 promotes the production of reactive oxygen species and apoptotic cell death during stress conditions) genes, since they have shown to be essentials for preventing the apoptotic mechanisms (programmed cell death) induced by oxidative stress ${ }^{51,52}$.

On the other hand, the presence of IS triggered the overexpression of the stress-related genes CCP1, CIR2, CTA1, GPX2, GRX4, MXR1, POS5, and TSA1. These genes encode different cytoplasmic and mitochondrial enzymatic activities, including cytochrome $c$ peroxidase, dehydrogenase, catalase, glutathione peroxidase, oxidoreductase, glutaredoxin, kinase, and peroxiredoxin, as crucial antioxidant defenses ${ }^{30,53,54}$. These activities belong to the glutathione and thioredoxin systems that are responsible for maintaining redox homeostasis through complex regulatory machinery. Intracellular glutathione levels have shown to be essential for increasing S. cerevisiae robustness to the stress caused by lignocellulose-derived inhibitors ${ }^{55}$. In addition, previous biochemical studies have suggested that thioredoxin is the predominant antioxidant system in yeast, and also showing important interconnections with the glutathione system ${ }^{30}$. Both glutathione and thioredoxin systems are cysteine-demanding protective processes, since this amino acid residue is easily oxidized by ROS compounds. Cysteine, together with methionine, is a primary sulfur amino acid. Therefore, sulfate assimilation pathway and the superpathway of sulfur amino acid biosynthesis were induced in response to IS in order to support the synthesis of these compounds. The overexpression of these pathways may also involve a third antioxidant system, based on methionine amino acid. Similar to cysteine, methionine residues are extremely sensitive to ROS compounds, thus generating methionine sulfoxide. This oxidized methionine residue can subsequently be reduced through the catalysis of methionine sulfoxide reductases that are encoded by MXR1 (which was also included within the overexpressed genes) and $M X R 2^{56}$, working as a natural scavenging mechanism to remove ROS compounds. Although these results seem to be contradictory with repression of BIR1 and STF2, it is important to consider that RNA was likely collected from a population with cells at different metabolic stages due to the presence of an external stressor. This could be also inferred from the fact that viable cells remain almost constant at 6,24 and $48 \mathrm{~h}$ when $40 \%$ or $60 \%$ 


\begin{tabular}{|c|c|}
\hline Biological Process & Genes $^{\mathrm{a}}$ \\
\hline \multicolumn{2}{|l|}{ Upregulated genes: } \\
\hline $\begin{array}{l}\text { Alpha amino acid metabolic } \\
\text { process, Allantoin degradation, } \\
\text { Glyoxylate cycle/TCA cycle }\end{array}$ & $\begin{array}{l}\text { ACO1, ACO2, ARG1, ARG3, ARG5,6, ASN1, CAR1, CPA1, DAL1, DAL3, DAL4, DAL5, } \\
\text { DAL7, ERV1, GLT1, HOM3, ICL1, IDH1, KAP123, LEU1, LEU4, LEU9, LYS1, LYS20, } \\
\text { MIX17, PGA3 }\end{array}$ \\
\hline Cellular respiration & ACO1, COR1, COX7, CYC1, CYT1, ICL1, IDH1, MIX17, QCR2, SDH2, SDH3, SDH4 \\
\hline Fe-S cluster assembly & CFD1, CIA2, ISA1, NAR1, YAH1 \\
\hline Response to oxidative stress & CTA1, GPX2, GRX4, TSA1 \\
\hline Ribosome biogenesis & $\begin{array}{l}\text { ALB1, BCP1, DHR2, DIM1, ECM1, EMG1, NHP2, NIP7, RLI1, RPL26B, RPS28A, RSM7, } \\
\text { YTM1 }\end{array}$ \\
\hline $\begin{array}{l}\text { Sulfur amino acid metabolic } \\
\text { process }\end{array}$ & $\begin{array}{l}\text { MET1, MET10, MET14, MET16, MET17, MET2, MET28, MET3, MET32, MET5, MET8, } \\
\text { MHT1, MMP1, MXR1, STR3, SUL1, SUL2 }\end{array}$ \\
\hline Translation & $\begin{array}{l}\text { CDC33, MNP1, MRPL27, MRPL28, MRPL32, NHP2, RLI1, RML2, RPL23B, RPL26B, } \\
\text { RPL29, RPL9A, RPS28A, RSM7 }\end{array}$ \\
\hline \multicolumn{2}{|l|}{ Downregulated genes: } \\
\hline Autophagy & APE1, ATG15, ATG17, ATG19, ATG20, ATG23, ATG29, ATG34, SNX4, SNX41, VPS41 \\
\hline Cell cycle phase transition & CLN3, MBP1, RLM1, SWI4, WHI5, (CDC7, CTR9, STE20, XBP1) \\
\hline Cell division & $\begin{array}{l}\text { CIN8, KRE28, NUF2, RNR3, SLK19, (ADY3, BIR1, BRN1, CDC37, CDC7, CLN3, CNM67, } \\
\text { DON1, KAR1, MPC54, PDS5, SHS1, SMC2, SMC3, SMC4, SSD1, TPK1) }\end{array}$ \\
\hline Chromatin organization & BRE1, CDC7, CTR9, ELF1, MCM10, POB3, RTF1 \\
\hline DNA repair I & BRN1, PDS5, RAD17, RAD50, RAD61, RAD9, SMC2, SMC3, SMC4, XRS2 \\
\hline DNA repair II & HFM1, MLH3, MSH2, MSH4, MSH5, RAD16, RAD2, RAD26, RAD7, UBP15 \\
\hline Fatty acid oxidation & FAA1, FAA2, POX1, PXA1, PXA2 \\
\hline Gluconeogenesis & FYV10, GID7, GPM2, MDH2, TDH1, UBC8, VID24, VID28, VID30 \\
\hline Glycolysis/Gluconeogenesis & PYK2, HXK1, TDH1, YOR283W, ERR3, GPM2 \\
\hline Maltose metabolic process & IMA1, MAL31, MAL32 \\
\hline $\begin{array}{l}\text { Phosphorus metabolic process, } \\
\text { TCA cycle }\end{array}$ & $\begin{array}{l}\text { CIT3, CYR1, FMP48, GDH3, HFA1, IDP3, KDX1, MDH2, PBS2, PTK2, PTP2, SHH3, } \\
\text { YBR139W, YJR149W }\end{array}$ \\
\hline Proteinase $A$ and $B$ & PAI3, PEP4, PRB1 \\
\hline Proteolysis & PCI8, RPN1, RRI1, (FYV10, UBP15, UBP16, UBP2, UBP9, VID24, VID30, YGR066C) \\
\hline $\begin{array}{l}\text { RNA metabolic process, } \\
\text { ribosome biogenesis }\end{array}$ & $\begin{array}{l}\text { BUD22, KRI1, MAK16, NMD2, RRP14, RRP36, SAS10, TAP42, TOR2, UPF3, (REX3, RIO1, } \\
\text { RPM1, SNU66, SQS1) }\end{array}$ \\
\hline RNA splicing & CLF1, LIN1, PRP11, PRP3, SLU7, SNU66, SQS1, THP3, YJU2 \\
\hline $\begin{array}{l}\text { Trehalose and glycogene } \\
\text { metabolic processes, generation } \\
\text { of precursor metabolites and } \\
\text { energy, response to stress }\end{array}$ & $\begin{array}{l}\text { ALD4, AQY2, ATH1, COX5B, DAK1, DCS1, DCS2, DDR2, ECM4, EGO4, EMI2, FMP33, } \\
\text { FMP45, GAD1, GCY1, GDB1, GGA1, GIP2, GLC3, GLG1, GLK1, GND2, GOR1, GPD1, } \\
\text { GPG1, GPH1, GSC2, GSY1, GSY2, HBT1, HSP104, HSP26, HSP42, HSP78, HXK1, HXT7, } \\
\text { IGD1, MHO1, MSC1, NDE2, NTH1, OM45, PGM2, PNC1, RGI1, RTC3, RTN2, SBP1, } \\
\text { SDS24, SFA1, SOL4, SPI1, SSE2, STF2, TFS1, TKL2, TMA17, TPK1, TPS1, TPS2, TPS3, } \\
\text { TSL1, UGA1, UGP1, UIP4, YDL124W, YGP1, YJL144W, YLR149C, YLR345W, YPL247C, } \\
\text { YRO2, ZWF1 (BIR1, EIS1, FUN19, GRX1, HSP30, HSP31, IZH4, MTL1, TMC1, TSA2, } \\
\text { YBL111C, YDR391C, YIL108W, YKR011C) }\end{array}$ \\
\hline
\end{tabular}

Table 4. Grouped genes based on STRING protein-protein interaction analysis. ${ }^{a}$ Other differentially expressed genes with similar function and not visualized by STRING analysis are indicated in brackets.

IS (w/w) were present (RNA was collected from cells after $4 \mathrm{~h}$ of fermentation). Then, cell death might be more severe within $0-6 \mathrm{~h}$, while remaining cells might enter in a quiescent state (as suggested by the downregulation of cell cycle) towards increasing its robustness under these conditions. Induction of stress-related mechanisms such as glutathione, thioredoxin and methionine-based scavenging systems might therefore have an important role in ROS protection and viability maintenance in presence of IS. Also, other non-identified mechanisms (e.g. changes in yeast cell wall) might also play a crucial role towards facing IS-induced stress.

In brief, the present study underlines the presence of high IS content as an important stress factor that promotes physical, physiological and genetic changes on fermentative microorganisms. Cells respond to IS with membrane wrinkling and deformation, as seen with other physical and/or chemical stressors (e.g. osmotic stress, desiccation, ethanol, etc.). Several multi-stress response genes are repressed, leading to the accumulation of intracellular ROS and ultimately affecting yeast viability and fermentation performance. Also, it is important to highlight the synergistic stress effect promoted by the simultaneous presence of lignocellulose-derived inhibitors and IS. Dealing with new engineering strategies such as evolutionary engineering, and further evaluating the general stress response mechanisms, ROS tolerance, and cell cycle arrest at molecular level is of utmost importance to fully comprehend and overcome the effect caused by IS on yeast cells. Furthermore, triggering different stress response mechanisms on yeast cells, especially those related with antioxidant activities (e.g. glutathione, thioredoxin and/or methionine-based scavenging systems) or those preventing programed cell death (e.g. BIR1 and/or $S T F 2$ ) seems to be crucial to obtain novel and more robust yeasts strains for the lignocellulosic industry.

\section{Data Availability}

All data generated or analyzed during this study and the links to the corresponding databases are included in this published article (and its Supplementary Information files). 


\section{References}

1. dos Santos, L. V. et al. Second-generation ethanol: The need is becoming a reality. Ind. Biotechnol. 12, 40-57 (2016).

2. Balan, V., Chiaramonti, D. \& Kumar, S. Review of US and EU initiatives toward development, demonstration, and commercialization of lignocellulosic biofuels. Biofuel Bioprod. Bior. 7, 732-759 (2013).

3. Tomás-Pejó, E., Oliva, J. M., Ballesteros, M. \& Olsson, L. Comparison of SHF and SSF processes from steam-exploded wheat straw for ethanol production by xylose-fermenting and robust glucose-fermenting Saccharomyces cerevisiae strains. Biotechnol. Bioeng. 100, 1122-1131 (2008).

4. Moreno, A. D., Alvira, P., Ibarra, D. \& Tomás-Pejó, E. Production of ethanol from lignocellulosic biomass. In Production of Platform Chemicals from Sustainable Resources (eds Fang, Z., Smith, R. L. \& Qi, X.) 375-410 (Springer Nature Singapore, 2017).

5. Salehi Jouzani, G. \& Taherzadeh, M. J. Advances in consolidated bioprocessing systems for bioethanol and butanol production from biomass: a comprehensive review. Biofuel Research Journal 2(1), 152-195 (2015).

6. Koppram, R., Tomás-Pejó, E., Xiros, C. \& Olsson, L. Lignocellulosic ethanol production at high-gravity: challenges and perspectives. Trends Biotechnol. 32, 46-53 (2014).

7. Ding, M. Z. et al. Proteomic research reveals the stress response and detoxification of yeast to combined inhibitors. PLoS One 7, e43474, https://doi.org/10.1371/journal.pone.0043474 (2012).

8. Lv, Y. J. et al. Proteomic analysis reveals complex metabolic regulation in Saccharomyces cerevisiae cells against multiple inhibitors stress. Appl. Microbiol. Biotechnol. 98, 2207-2221 (2014).

9. Cunha, J. T., Romaní, A., Costa, C. E., Sá-Correia, I. \& Domingues, L. Molecular and physiological basis of Saccharomyces cerevisiae tolerance to adverse lignocellulose-based process conditions. Appl. Microbiol. Biotechnol. 103(1), 159-175 (2019).

10. Stenberg, K., Bollók, M., Réczey, K., Galbe, M. \& Zacchi, G. Effect of substrate and cellulase concentration on simultaneous saccharification and fermentation of steam-pretreated softwood for ethanol production. Biotechnol. Bioeng. 68, 204-210 (2000).

11. Tomás-Pejó, E., Oliva, J. M., González, A., Ballesteros, I. \& Ballesteros, M. Bioethanol production from wheat straw by the thermotolerant yeast Kluyveromyces marxianus CECT 10875 in a simultaneous saccharification and fermentation fed-batch process. Fuel 88, 2142-2147 (2009).

12. Sonderegger, M. et al. Fermentation performance of engineered and evolved xylose-fermenting Saccharomyces cerevisiae strains. Biotechnol. Bioeng. 87, 90-98 (2004).

13. Tomás-Pejó, E., Ballesteros, M., Oliva, J. M. \& Olsson, L. Adaptation of the xylose fermenting yeast Saccharomyces cerevisiae F12 for improving ethanol production in different fed-batch SSF processes. J. Ind. Microbiol. Biotechnol. 37, 1211-1220 (2010).

14. Mattheus, N., Ekramoddoullah, A. K. \& Lee, S. P. Isolation of high-quality RNA from white spruce tissue using a three-stage purification method and subsequent cloning of a transcript from the PR-10 gene family. Phytochem. Anal. 14(4), 209-215 (2003).

15. Moreno, A. D. \& Olsson, L. Pretreatment of lignocellulosic feedstocks. In Extremophilic enzymatic processing of lignocellulosic feedstocks to bioenergy (eds Sani, R. \& Krishnaraj, R.) 31-52 (Springer, 2017).

16. Nielsen, F., Tomás-Pejó, E., Olsson, L. \& Wallberg, O. Short-term adaptation during propagation improves the performance of xylose-fermenting Saccharomyces cerevisiae in simultaneous saccharification and co-fermentation. Biotechnol. Biofuels 8, 219, https://doi.org/10.1186/s13068-015-0399-4 (2015).

17. Gomes, A., Fernandes, E. \& Lima, J. L. Fluorescence probes used for detection of reactive oxygen species. J. Biochem. Biophys. Methods 65, 45-80 (2005).

18. Narayanan, V., Schelin, J., Gorwa-Grauslund, M., van Niel, E. W. \& Carlquist, M. Increased lignocellulosic inhibitor tolerance of Saccharomyces cerevisiae cell populations in early stationary phase. Biotechnol. Biofuels 10, 114, https://doi.org/10.1186/s13068-0170794-0 (2017).

19. Alonso, R. et al. Babelomics 5.0: functional interpretation for new generations of genomic data. Nucleic Acids Res. 43, W117-W121 (2015).

20. Väremo, L., Nielsen, J. \& Nookaew, I. Enriching the gene set analysis of genome-wide data by incorporating directionality of gene expression and combining statistical hypotheses and methods. Nucleic Acids Res. 41, 4378-4391 (2013).

21. Balakrishnan, R. et al. YeastMine-an integrated data warehouse for Saccharomyces cerevisiae data as a multipurpose tool-kit. Database 2012, bar062; 10.1093/database/bar062 (2012).

22. Szklarczyk, D. et al. The STRING database in 2017: quality-controlled protein-protein association networks, made broadly accessible. Nucleic Acids Res. 45, D362-D368 (2017).

23. Jørgensen, H., Vibe-Pedersen, J., Larsen, J. \& Felby, C. Liquefaction of lignocellulose at high-solids concentrations. Biotechnol. Bioeng. 96(5), 862-870 (2007).

24. Adya, A. K., Canetta, E. \& Walker, G. M. Atomic force microscopic study of the influence of physical stresses on Saccharomyces cerevisiae and Schizosaccharomyces pombe. FEMS Yeast Res. 6, 120-128 (2006).

25. Canetta, E., Walker, G. M. \& Adya, A. K. Nanoscopic morphological changes in yeast cell surfaces caused by oxidative stress: An atomic force microscopic study. J. Microbiol. Biotechnol. 19, 547-555 (2009).

26. Zhang, M., Shi, J. \& Jiang, L. Modulation of mitochondrial membrane integrity and ROS formation by high temperature in Saccharomyces cerevisiae. Electron. J. Biotechnol. 18, 202-209 (2015).

27. Bergemann, T. L. \& Wilson, J. Proportion statistics to detect differentially expressed genes: a comparison with log-ratio statistics. BMC Bioinformatics 12, 228, https://doi.org/10.1186/1471-2105-12-228 (2011).

28. Kobayashi, N., McClanahan, T. K., Simon, J. R., Treger, J. M. \& McEntee, K. Structure and functional analysis of the multistress response gene DDR2 from Saccharomyces cerevisiae. Biochem. Biophys. Res. Commun. 229, 540-547 (1996).

29. Vilella, F., Herrero, E., Torres, J. \& de la Torre-Ruiz, M. A. Pkcl and the upstream elements of the cell integrity pathway in Saccharomyces cerevisiae, Rom2 and Mtl1, are required for cellular responses to oxidative stress. J. Biol. Chem. 280, 9149-9159 (2005).

30. Morano, K. A., Grant, C. M. \& Moye-Rowley, W. S. The response to heat shock and oxidative stress in Saccharomyces cerevisiae. Genetics 190, 1157-1195 (2012).

31. Święciło, A. Cross-stress resistance in Saccharomyces cerevisiae yeast-new insight into an old phenomenon. Cell Stress Chaperones 21, 187-200 (2016).

32. Lillie, S. H. \& Pringle, J. R. Reserve carbohydrate metabolism in Saccharomyces cerevisiae: responses to nutrient limitation. J. Bacteriol. 143, 1384-1394 (1980).

33. Hohmann, S. \& Mager, W. H. Yeast stress responses (Springer-Verlag, 1997).

34. Xiros, C. et al. Toward a sustainable biorefinery using high-gravity technology. Biofuel Bioprod. Bior. 11, 15-27 (2017).

35. Stoupis, T., Stewart, G. G. \& Stafford, R. A. Hydrodynamic shear damage of brewer's yeast. J. Am. Soc. Brew. Chem. 61, 219-225 (2003).

36. Pillet, F. et al. Uncovering by atomic force microscopy of an original circular structure at the yeast cell surface in response to heat shock. BMC Biol. 12, 6, https://doi.org/10.1186/1741-7007-12-6 (2014).

37. Canetta, E., Adya, A. K. \& Walker, G. M. Atomic force microscopic study of the effects of ethanol on yeast cell surface morphology. FEMS Microbiol. Lett. 255, 308-315 (2006).

38. Schiavone, M. et al. Evidence for a role for the plasma membrane in the nanomechanical properties of the cell wall as revealed by an atomic force microscopy study of the response of Saccharomyces cerevisiae to ethanol stress. Appl. Environ. Microbiol. 82, 4789-4801 (2016).

39. Herman, P. K. Stationary phase in yeast. Curr. Opin. Microbiol. 5, 602-607 (2002). 
40. Shi, L. \& Tu, B. P. Acetyl-CoA induces transcription of the key G1 cyclin CLN3 to promote entry into the cell division cycle in Saccharomyces cerevisiae. Proc. Natl. Acad. Sci. USA 110, 7318-7323 (2013).

41. Klosinska, M. M., Crutchfield, C. A., Bradley, P. H., Rabinowitz, J. D. \& Broach, J. R. Yeast cells can access distinct quiescent states. Genes Dev. 25, 336-349 (2011).

42. Mayer, C. \& Grummt, I. Ribosome biogenesis and cell growth: mTOR coordinates transcription by all three classes of nuclear RNA polymerases. Oncogene 25, 6384-6391 (2006).

43. An, Z. et al. Autophagy is required for $\mathrm{G}_{1} / \mathrm{G}_{0}$ quiescence in response to nitrogen starvation in Saccharomyces cerevisiae. Autophagy 10, 1702-1711 (2014)

44. Shaltiel, I. A., Krenning, L., Bruinsma, W. \& Medema, R. H. The same, only different - DNA damage checkpoints and their reversal throughout the cell cycle. J. Cell Sci. 128, 607-620 (2015).

45. de Nadal, E., Ammerer, G. \& Posas, F. Controlling gene expression in response to stress. Nat. Rev. Genet. 12, 833-845 (2011).

46. Caspeta, L., Castillo, T. \& Nielsen, J. Modifying yeast tolerance to inhibitory conditions of ethanol production processes. Front. Bioeng. Biotechnol. 3, 184, https://doi.org/10.3389/fbioe.2015.00184 (2015).

47. Aung-Htut, M. T., Ayer, A., Breitenbach, M. \& Dawes, I. W. Oxidative stresses and ageing. In Aging Research in Yeast (eds Breitenbach, M., Jazwinski, S. M. \& Laun, P.) 13-54 (Springer, 2012).

48. Pereira, M. D., Eleutherio, E. C. A. \& Panek, A. D. Acquisition of tolerance against oxidative damage in Saccharomyces cerevisiae. BMC Microbiol. 1, 11, https://doi.org/10.1186/1471-2180-1-11 (2001).

49. Boiteux, S. \& Jinks-Robertson, S. DNA repair mechanisms and the bypass of DNA damage in Saccharomyces cerevisiae. Genetics 193, 1025-1064 (2013).

50. Gangloff, S. \& Arcangioli, B. DNA repair and mutations during quiescence in yeast. FEMS Yeast Res. 17, fox002; https://doi. org/10.1093/femsyr/fox002 (2017).

51. Walter, D., Wissing, S., Madeo, F. \& Fahrenkrog, B. The inhibitor-of-apoptosis protein Birlp protects against apoptosis in S. cerevisiae and is a substrate for the yeast homologue of Omi/HtrA2. J. Cell Sci. 119, 1843-1851 (2006).

52. López-Martínez, G., Rodríguez-Porrata, B., Margalef-Català, M. \& Cordero-Otero, R. The STF2p hydrophilin from Saccharomyces cerevisiae is required for dehydration stress tolerance. PLoS One 7, e33324, https://doi.org/10.1371/journal.pone.0033324 (2012).

53. Strand, M. K. et al. POS5 gene of Saccharomyces cerevisiae encodes a mitochondrial NADH kinase required for stability of mitochondrial DNA. Eukaryot. Cell 2, 809-820 (2003).

54. Lopes, J., Pinto, M. J., Rodrigues, A., Vasconcelos, F. \& Oliveira, R. The Saccharomyces cerevisiae genes, AIM45, YGR207c/CIR1 and YOR356w/CIR2, are involved in cellular redox state under stress conditions. Open Microbiol. J. 4, 75-82 (2010).

55. Ask, M., Mapelli, V., Höck, H., Olsson, L. \& Bettiga, M. Engineering glutathione biosynthesis of Saccharomyces cerevisiae increases robustness to inhibitors in pretreated lignocellulosic materials. Microb. Cell Fact. 12, 87, https://doi.org/10.1186/1475-2859-12-87 (2013).

56. Koc, A., Gasch, A. P., Rutherford, J. C., Kim, H. Y. \& Gladyshev, V. N. Methionine sulfoxide reductase regulation of yeast lifespan reveals reactive oxygen species-dependent and -independent components of aging. Proc. Natl. Acad. Sci. USA 101, 7999-8004 (2004).

\section{Acknowledgements}

Authors thank Professor Lisbeth Olsson (Chalmers University of Technology) for kindly providing S. cerevisiae F12 strain and Dr. Fernando Picó (IMDEA Energy Institute) for his valuable support in the AFM imaging. The National Research Agency of the Spanish Ministry of Science, Innovation and Universities and the Regional Government of Madrid are greatly acknowledged for funding this study via LIGNOYEAST (ENE2014-315 54912-R), ACMIBIO (ENE2017-86864-C2-2-R, AEI/FEDER, UE), and INSPIRA-1 (S2013/ABI-2783) projects.

\section{Author Contributions}

A.D.M. and E.T.P. performed and coordinated the study, analyzed the data, and prepared the manuscript. M.B. and C.G.F. contributed to coordinate the study and prepare the manuscript.

\section{Additional Information}

Supplementary information accompanies this paper at https://doi.org/10.1038/s41598-019-48733-w.

Competing Interests: The authors declare no competing interests.

Publisher's note: Springer Nature remains neutral with regard to jurisdictional claims in published maps and institutional affiliations.

(c) (i) Open Access This article is licensed under a Creative Commons Attribution 4.0 International

License, which permits use, sharing, adaptation, distribution and reproduction in any medium or format, as long as you give appropriate credit to the original author(s) and the source, provide a link to the Creative Commons license, and indicate if changes were made. The images or other third party material in this article are included in the article's Creative Commons license, unless indicated otherwise in a credit line to the material. If material is not included in the article's Creative Commons license and your intended use is not permitted by statutory regulation or exceeds the permitted use, you will need to obtain permission directly from the copyright holder. To view a copy of this license, visit http://creativecommons.org/licenses/by/4.0/.

(c) The Author(s) 2019 